\title{
Proposing a framework of game-based learning and assessment systems
}

\author{
Naidong Zhao, Beijing Institute of Fashion Technology, sxyznd@bift.edu.cn \\ Mingke Xiong, Beijing Zhongguancun Foreign Language School, minka.xiong@zgcschool.cn \\ Xihui Zhang, University of North Alabama,xzhang6@una.edu \\ Mark G. Terwilliger, University of North Alabama, mterwilliger@una.edu
}

\begin{abstract}
Using the methods of bibliometric analysis and content analysis, we collected and analyzed relevant literature on game-based learning and assessment systems. We explored the key elements, assessment contents, assessment methods, and the data mining process of game-based educational assessment. Finally, we proposed a framework of game-based learning and assessment systems. This framework emphasizes the universality of game-based learning and assessment systems and highlights the important role of an interaction behavior log in mining the learning data. This framework can not only be used for educational games but can also be extended to learning and assessment systems based on a simulation environment.
\end{abstract}

Keywords: game-based learning, educational games, assessment systems, cognitive science

\section{Introduction}

In the 21st century, with the explosive growth of information, the world is becoming flatter, more complex, and more interdependent. Consequently, the problems we are facing are becoming more complicated and more challenging. Therefore, we must think creatively and systematically and communicate collaboratively and effectively (Csapó \& Funke, 2017; Shute, 2011). The way to train and evaluate talent today is no longer simply a matter of imparting knowledge and testing it with multiple-choice questions. Some scholars have pointed out that in dynamic, opaque, and complicated problem environments, we should cultivate students' self-summary, self-reflection, self-monitoring, and lifelong learning ability (Greiff et al., 2014). The corresponding assessment should be a reflective assessment, which is to find ways to best evaluate students' ability to acquire key capabilities according to the new skills and standards in the 21 st century (Shute, 2011).

The Organization for Economic Cooperation and Development (OECD), an intergovernmental economic organization, has launched a large-scale study of comparative quality of research on student learning, the Program for International Student Assessment (PISA). Every three years, PISA measures the reading, mathematics, and science literacy of 15-year-old students. It is used to evaluate the ability of students to adapt their knowledge and skills later in life. In China's macroeconomic policy, the National Medium and Long-Term Education Reform and Development Plan (2010-2020) emphasizes the ability to improve students' learning, practice, and innovation. In practice, the reform of curriculum standards is being continuously carried out, and core literacy has become the focus (Zuo, 2016). Led by Beijing Normal University in 2012, the Joint Education Ministry Examination Center and eight other institutions nationwide jointly established the China Collaborative Innovation Center for Quality Monitoring of Basic Education to do monitoring and assessment studies (http://cicabeq.bnu.edu.cn/index.shtml). 


\section{Issues in Information Systems}

Volume 22, Issue 4, pp. 193-207, 2021

Compared with previous paper-and-pen tests, learning and assessment systems can record and collect the process data of students in greater detail. As a result, researchers have paid greater attention to these assessments (Shute, 2008; Shute et al., 2008; Squire, 2006; Williamson, 2004). Some studies have shown that web-based computer learning and assessment can generally improve students' learning outcomes (Shute \& Rahimi, 2017). There is still, however, a divide between computer-assisted learning, an educatorsupported activity, and online computer games, an activity students really enjoy. As such, being able to learn while playing a game is an important way to minimize this divide and improve student learning (Shute, 2011). Game-based learning, based on the educational theories and practices of experiential learning, active learning, and situational learning, serves as a potential complementary learning participation form that enhances the teaching process. It has been applied to all stages of education, including primary, secondary, and higher education (Scherer \& Tiemann, 2012). In game-based learning and assessment, the game can stimulate learners' interests and improve their learning outcomes. For educational researchers, the rich educational data produced from the interaction between students and games can by analyzed. The researchers can then have a better understanding of the students' learning process and the problems encountered during the process. This, in turn, enables them to improve the game design, starting a virtuous cycle.

A normal game is designed for entertainment, whereas an educational game is designed for teaching and learning. Whether a game is an educational game or not, a goal is set for the players so that they can overcome an obstacle by interacting with the simulation environment and finally achieve that goal. The problem-solving process usually starts from an initial state, with the help of strategies and methods, and continues to subsequent states until it finally reaches a target state (Dostál, 2015). The essence of the students' participation in educational games is a problem-solving process. Therefore, we can achieve the purpose of teaching through educational games and cultivate student problem-solving abilities through the process of the game. At the same time, we can evaluate the quality of student learning with game-based learning and assessment systems. As such, we need to have a framework (which is now lacking) of gamebased learning and assessment systems so that we can integrate students' cognition, metacognition, and emotion for improved educational effectiveness and efficiency. This research attempts to fill that research gap.

This paper proceeds with three main sections. We begin by presenting an overview of game-based learning and assessment systems research. Next, we present the methodology and data analysis results. Finally, we build a framework of game-based learning and assessment systems.

\section{Literature review}

\section{Game-based learning and assessment systems}

There is an essential difference between educational games and general-purpose games. Educational games need to teach knowledge and train skills. Therefore, there is a content model that describes what you want to teach and defines student-learning goals. According to their characteristics and purposes, the design of all educational games should be based on a learning content model. Assessment-focused educational games need to clearly define the concepts and standards by which students should be measured. The games should design storylines and interactive environments based on related functionalities and capabilities.

Halverson and Owen (2014) pointed out that a game-based assessment system can be divided into four layers: content models, game storylines, semantic templates, and learning metrics. The content models are the core of the whole system, defining what needs to be evaluated. The game storylines are set up according to the content models, enabling students to gain full interactive opportunities to demonstrate their familiarity 


\section{Issues in Information Systems}

Volume 22, Issue 4, pp. 193-207, 2021

with the content being examined. All of the student's interactive behavior will be stored in a log file. The semantic template is established by analyzing student behavior in the log file. All of these behaviors can have an impact on the different indicators of student learning. These student learning indicators can be used to more effectively select test questions or dynamically adjust a test's difficulty level (Halverson \& Owen, 2014). Researchers have also built a comprehensive assessment model which focuses on four main aspects that include assessment objects, assessment dimensions, representation indicators, and data support (Zheng et al., 2016).

\section{Game-based problem-solving process}

To solve a problem, students first need to be able to identify the solution as a single goal. For well-defined problems, this goal is often given directly in the problem description. For problems that are not well defined, however, students need to define a reasonable goal according to the existing conditions. They can then analyze the difference between the current state and the final goal based on the problem description. Students then develop strategies according to the available means to complete the transition from the current state to the final goal. There are three main components in problem-solving: the initial state, the final goal, and the available means. Different problem-solvers often adopt different methods of transitioning, which also explains the diversity of strategies. The game-based problem-solving process may also be seen as the transformation from the initial state to the final state through a variety of strategies and methods. The game enhances the problem-solving process because it is fun. Studies have shown that game-based learning can be a good combination of content learning and gaming, which improves learners' interest and motivation in learning (Chang et al., 2017; Hummel et al., 2017). Other researchers explore changes in cognitive processes in game-based problem-solving (Funke, 2010). Some researchers study the influence of metacognitive strategies on problem-solving in games or simulation environments (Kim et al., 2009; Scherer \& Tiemann, 2012).

Although many researchers realize the value of large amounts of data generated by students on the platform after a game is launched online, the research on this interactive data is insufficient. In particular, the existing research on the interactive data generated from educational games has not been well integrated with the research findings in cognitive science. The research findings in cognitive science do not guide the mining of educational interaction data, and the mining results can hardly promote the study of cognitive science. In the field of problem-solving, cognitive science had a more comprehensive study of the subject in the 1980s (Chi, 1983). The commonly used strategies and experimental methods related to problem-solving have been thoroughly summarized. The assessment method was limited by the paper-and-pen form assessment at that time and was not able to be promoted on a large scale. The purpose of assessment in general, and the purpose of educational assessment in particular, were slightly different. These research results, however, can still provide a good guide for current educational game assessment. Unfortunately, few educational game systems draw on their experience to combine educational game interaction data with aspects of cognition, metacognition, and emotion in game problem-solving. Some educational game systems fail to introduce the framework of educational research entirely. Therefore, based on previous cognitive psychology research, this study proposes a basic design framework of game-based learning and assessment systems through literature review and content analysis. Based on the key elements of the primary design framework, we present the assessment process, assessment contents, and assessment methods of educational games, as well as the integration of interactive data mining, as a framework to provide overarching guidance for future research. 


\section{Methodology and analysis results}

\section{Research design}

This study investigates the existing literature on educational game assessment using the methods of bibliometric analysis and content analysis. It also explores the components of the existing educational game assessment systems, as well as the assessment content, assessment method, and mining of the related process data. The specific implementation steps are as follows.

First, we took Web of Science (WoS) as the sample database, used "game-based assessment" as the keyword, set the time span as 1996-2017, selected the Core Collection, searched, evaluated the search results, and ended up with 350 usable literature items. We used "game-based assessment" but not "learning" as a search keyword because a paper that talks about "game-based assessment" is typically related to "learning" but not vice versa. A usable literature item means that the item focuses on gamed-based assessment and also fits our research purpose. We then imported the key information of the usable documents into CiteSpace 5.1.R5, and analyzed the co-word network and content clustering, respectively. We then drew the hot spots of the educational game assessments, analyzed the hot content, and extracted the key elements that are needed to construct the basic design framework.

Second, based on the 350 usable documents, we removed all other journal sources, focused on the journal of Computers \& Education, used "game-based" as the keyword, searched, and found 119 papers. We only used the literature from the journal of Computers \& Education for two reasons: (1) The journal is most relevant and has been publishing quality articles focusing on "game-based" research; (2) this will make our data analysis more manageable but still very much representative. Thirty-nine of the resulting literature did not involve any assessment (e.g., testing teachers' acceptance of educational games), and thus were excluded from further analysis. Finally, we ended up with 80 usable documents. Through the study of literature coding, we summarized the research situation of educational game assessment in assessment content, assessment method, and interactive data. In the following sections, the tables show the results of our data analysis of the literature items, and the figures show the proposed framework of game-based learning and assessment systems.

\section{Analysis of results}

\section{Key elements extraction by bibliometric analysis}

We imported the 350 usable documents from WoS into CiteSpace 5.1.R5. Using the Pathfinder algorithm and the LLR (logarithm of the likelihood ratio) clustering algorithm, we set the display cluster labels (see Table 1). 
Table 1: Center Degree Word Frequency (Count $>=5 \&$ Centrality $>=0.08$ )

\begin{tabular}{|l|l|l|l|}
\hline Count & Centrality & Year & Keyword | Noun Phase \\
\hline 48 & 0.22 & 2007 & game-based learning \\
\hline 38 & 0.27 & 2010 & serious game \\
\hline 25 & 0.28 & 2009 & educational game \\
\hline 25 & 0.28 & 2007 & learning process \\
\hline 22 & 0.13 & 2011 & game-based assessment \\
\hline 21 & 0.08 & 2012 & control group \\
\hline 14 & 0.27 & 2011 & learning outcome \\
\hline 10 & 0.08 & 2006 & computer game \\
\hline 9 & 0.17 & 2015 & experimental group \\
\hline 9 & 0.13 & 2010 & learning motivation \\
\hline 9 & 0.22 & 2013 & game-based approach \\
\hline 6 & 0.24 & 2011 & assessment tool \\
\hline 5 & 0.11 & 2015 & Bayesian network \\
\hline
\end{tabular}

As shown in Table 1, the three most frequently ranked terms, "game-based learning," "serious game," and "educational game," as well as three other terms, "game-based assessment," "computer game," and "gamebased approach," are all pointing to the subject of the research "game-based learning and assessment." All six of the terms have a high degree of centrality. We removed these terms that point to our research topic and then extracted key elements that form the basic design framework for game evaluation. The key elements (ordered by count from high to low) are "learning process," "control group," "learning outcome," "experimental group," "learning motivation," "assessment tool," and "Bayesian network." These key terms can be used to represent the focus of game-based learning and assessment.

\section{Assessment methods and content extraction by literature coding statistics and analysis}

This section summarizes the methods and contents of the existing educational game system evaluations. Since most educational games are not focused on testing, this summary includes all articles about educational games published in Computers \& Education between 2012 and 2016. This is not limited to only game reviews.

We collected 80 usable articles from Computers \& Education and manually extracted the educational game assessment data from each article by the method mentioned in the second step of the research design. We also counted the number of articles corresponding to the year from 2012 to 2016 as shown in Table 2. We showed the number of articles per year to better illustrate the trend change of each method over the years.

Table 2: Educational Game Assessment Experimental Data Acquisition Methods Statistics

\begin{tabular}{|c|c|c|c|c|c|c|}
\hline \multicolumn{2}{|c|}{ Method } & 2012 & 2013 & 2014 & 2015 & 2016 \\
\hline \multicolumn{2}{|c|}{ Pre-test \& Post-test } & 7 & 13 & 5 & 14 & 12 \\
\hline \multicolumn{2}{|c|}{$\begin{array}{l}\text { Questionnaire (pre/post questionnaire/in-game/online } \\
\text { survey/online quiz/inquiry) }\end{array}$} & 5 & 17 & 7 & 21 & 12 \\
\hline \multicolumn{2}{|c|}{$\begin{array}{l}\text { Log data (Game file/comments cards/files and log files/web } \\
\log / \text { server record and store data) }\end{array}$} & 2 & 0 & 1 & 0 & 0 \\
\hline \multirow{3}{*}{ Others } & Onsite coordinator's observations & 0 & 1 & 0 & 0 & 0 \\
\hline & Feedback & 0 & 2 & 0 & 0 & 0 \\
\hline & Interviews & 2 & 0 & 0 & 1 & 1 \\
\hline
\end{tabular}




\section{Issues in Information Systems}

Volume 22, Issue 4, pp. 193-207, 2021

We concluded that there are many methods that researchers can use to assess data. Most articles use the pre-test -> game intervention -> post-test design pattern to test whether educational game intervention helps students improve related learning performance. Therefore, the assessment of these systems is mainly done using pre-test and post-test data. Few systems extract basic interactive data such as log data for simple assessment even though many of these tests are used to give appropriate feedback in the game. Thus, the existing work is not sufficient for the research of embedded assessment of educational games. Most of the tests are carried out with the results of student performance, but the analysis of student behavior is inadequate.

The above description is the statistical analysis of the experimental data acquisition and experimental mode. The assessment content, however, is the core of the assessment systems. Therefore, we conducted a manual one-by-one extraction and compiled statistics on 48 articles (see Appendix A for the complete list of the 48 articles) that have addressed the assessment contents of the educational games involved in the available 80 of the usable literature items. In the end, we found that educational games are most concerned with student motivation and learning interest. Specific concerns include learning attitude, learning motivation, satisfaction, enjoyment, and engagement. Of the 48 usable articles, 34 of them made reviews in this area, most of which were self-explanatory. The specific articles in this area are shown in Table 3.

Table 3: Learning Motivation and Learning Interest

\begin{tabular}{|l|l|}
\hline $\begin{array}{l}\text { Assessment } \\
\text { Content }\end{array}$ & Articles \\
\hline $\begin{array}{l}\text { Learning } \\
\text { attitudes }\end{array}$ & $\begin{array}{l}\text { Hainey et al. (2013); Hwang et al. (2013); Hwang et al. (2012); Schmitz et al. } \\
\text { (2015); Snow et al. (2015); Sung \& Hwang (2013) }\end{array}$ \\
\hline $\begin{array}{l}\text { Learning } \\
\text { motivation }\end{array}$ & $\begin{array}{l}\text { All et al. (2015); Cagiltay et al. (2015); Denner et al. (2012); Erhel \& Jamet (2013); } \\
\text { Furió et al. (2013); Guo \& Goh (2016); Hainey et al. (2013); Hwang et al. (2015); } \\
\text { Ozcelik et al. (2013); Ronimus et al. (2014); Sampayo-Vargas et al. (2013); Smith et } \\
\text { al. (2013); Sung \& Hwang (2013); Wang (2015) }\end{array}$ \\
\hline $\begin{array}{l}\text { Satisfaction or } \\
\text { enjoyment }\end{array}$ & $\begin{array}{l}\text { Barzilai \& Blau (2014); Castellar et al. (2015); Guo \& Goh (2016); Hooshyar et al. } \\
\text { (2016); Hwang et al. (2012): Kim \& Jang (2015); Kim \& Shute (2015); Peng et al. } \\
\text { (2016); Ronimus et al. (2014); Warren et al. (2012) }\end{array}$ \\
\hline Engagement & $\begin{array}{l}\text { Adams \& Clark (2014); Barab et al. (2012); Chen \& Chiu (2016); Clark et al. } \\
\text { (2016); Filsecker \& Hickey (2014); Furió et al. (2013); Law \& Chen (2016); } \\
\text { Robertson (2012); Wang (2015) }\end{array}$ \\
\hline
\end{tabular}

There exist articles that focus on student metacognition. The most popular metacognition is self-efficacy, and another relevant concern is the improvement of the skills taught by the game (see Table 4). Note that other aspects of metacognition, due to less attention, are excluded in the summary. 
Table 4: Metacognition and Promotion of Skills

\begin{tabular}{|l|l|}
\hline Assessment Content & Articles \\
\hline $\begin{array}{l}\text { Self-efficacy/Perceived } \\
\text { ability/Perceived mastery of learning }\end{array}$ & $\begin{array}{l}\text { Barzilai \& Blau (2014); Kim \& Jang (2015); Law \& Chen } \\
\text { (2016); Le Hénaff et al. (2015); Meluso et al. (2012); Schmitz } \\
\text { et al. (2015); Sung \& Hwang (2013); Wang (2015) }\end{array}$ \\
\hline $\begin{array}{l}\text { Performance/Skills } \\
\text { score/Competencies score/Learning } \\
\text { outcome/Achievement/Score }\end{array}$ & $\begin{array}{l}\text { Aesaert \& van Braak (2015); All et al. (2015); All et al. (2016); } \\
\text { Castellar et al. (2015); Chen \& Chiu (2016); Clark et al. }\end{array}$ \\
& $\begin{array}{l}\text { (2016); Erhel \& Jamet (2013): Guo \& Goh (2016); Hooshyar et } \\
\text { al. (2016); Hwang et al. (2016); Hwang \& Wang (2016); }\end{array}$ \\
& $\begin{array}{l}\text { Hwang et al. (2013); Robertson (2012); Sampayo-Vargas et al. } \\
\text { (2013); Smith et al. (2013); Ventura et al. (2013); Warren et al. } \\
\text { (2012); Wouters \& Van Oostendorp (2013); Yang (2015); } \\
\text { Yang \& Chang (2013) }\end{array}$ \\
\hline
\end{tabular}

The last indicator of concern is the interactive behavior of the students. The characteristics of interactive behavior, however, will change with a specific game in many cases. Therefore, specific indicators will also change with the specific game (see Table 5). Note that research studies included in Tables 3, 4, and 5 are not listed in the References section but are included in Appendix A.

Table 5: Interactive Behavior of the Students

\begin{tabular}{|l|l|}
\hline Assessment Content & Articles \\
\hline $\begin{array}{l}\text { Time/Spent time/Completion } \\
\text { time/Session duration }\end{array}$ & $\begin{array}{l}\text { Corral et al. (2014); Feldman et al. (2014); Ronimus et al. } \\
\text { (2014); Soflano et al. (2015a); Soflano et al. (2015b) }\end{array}$ \\
\hline $\begin{array}{l}\text { Different feedback types on } \\
\text { knowledge acquisition }\end{array}$ & Hooshyar et al. (2016) \\
\hline Average actions used per attempt & Clark et al. (2016) \\
\hline Frequency of usage & Wang (2015) \\
\hline Reading time & Cagiltay et al. (2015); Ozcelik et al. (2013) \\
\hline In-game behaviors & Cheng et al. (2015) \\
\hline
\end{tabular}

According to the conclusion, the assessment of these above indicators mostly takes the form of selfstatements. A few projects have taken into consideration some simple behavioral statistics and behavioral patterns during the assessment, such as the average time spent on interaction. This behavioral statistical information from the side reflects the high student cognitive level. There is no single framework, however, describing the relationship between behavior patterns and assessment capabilities. This is probably because most studies do not design game interaction based on a competency theoretical model.

We will now use our analysis results to attempt the construction of a framework model of game-based learning and assessment systems. In the next section, we will use these findings of game-based data acquisition methods, learning motivation and interest, metacognition and skill promotion, and student interactive behavior to build such a model.

\section{Model construction}

The five key elements of the basic design framework extracted from the above bibliometric analysis are: learning process, learning motivation, assessment tool or Bayesian network, control group or experimental group, and learning outcomes. From the above literature coding analysis, we get the assessment content (including learning motivation and interest, metacognition, skills upgrading), assessment methods, and 


\section{Issues in Information Systems}

Volume 22, Issue 4, pp. 193-207, 2021

interactive data. We compare the five elements obtained from the bibliometric analysis with the results obtained by coding analysis, merge the elements needed, and retain other elements. The prototype of the basic design framework for the game-based learning and assessment systems can be obtained (see Figure 1). From the prototype, we can find that the learning process, assessment content (including learning motivation and interests, metacognition, and skills upgrading), assessment methods and tools, interactive data, and experimental comparison together constitute the basic framework model.

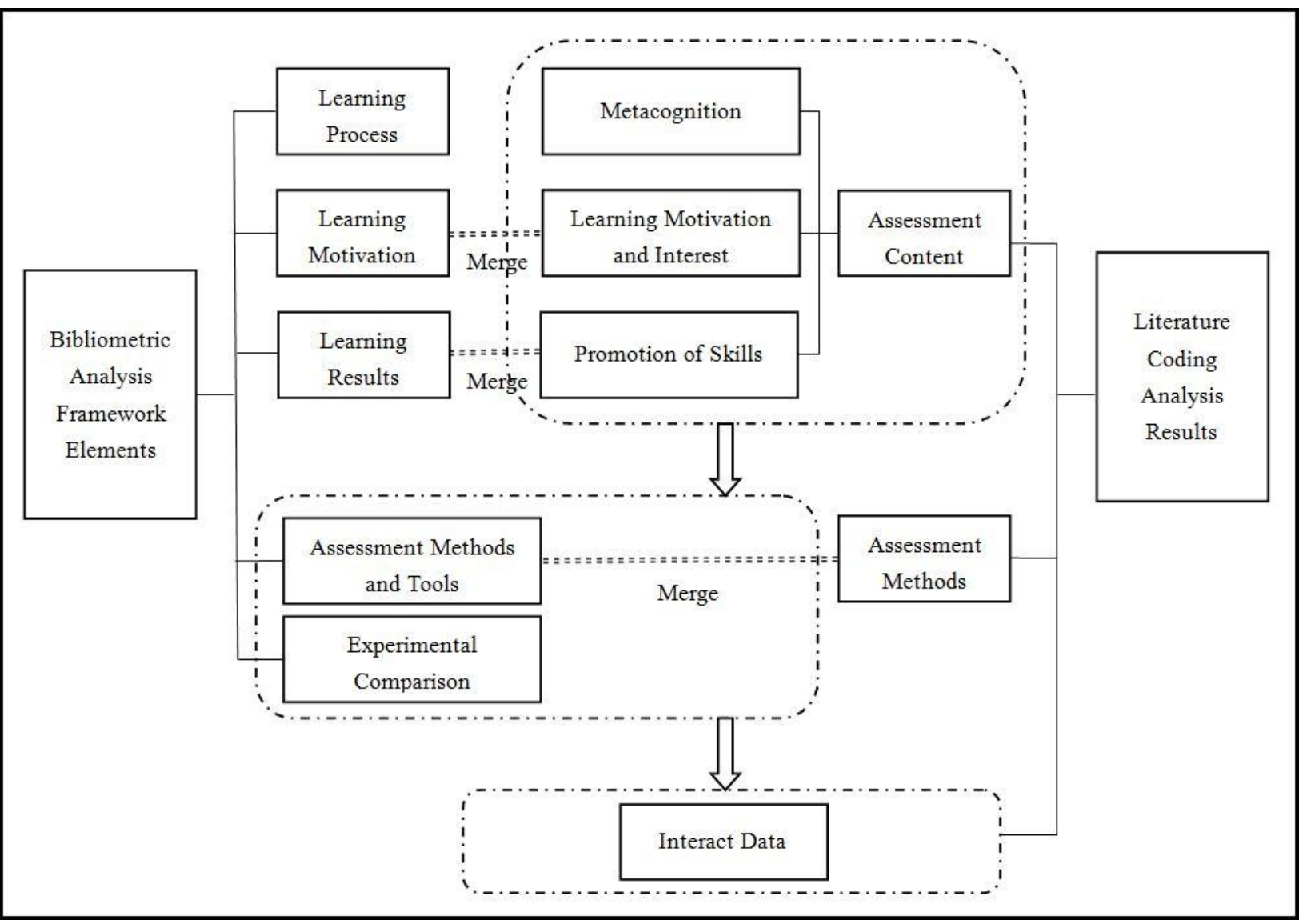

Figure 1: Prototype Framework Model of Game-Based Learning and Assessment Systems

The Framework Model of Game-Based Learning and Assessment Systems (FMGBLAS) should first emphasize the attention to the learning process. We can then have a basic process framework as shown in Figure 2.

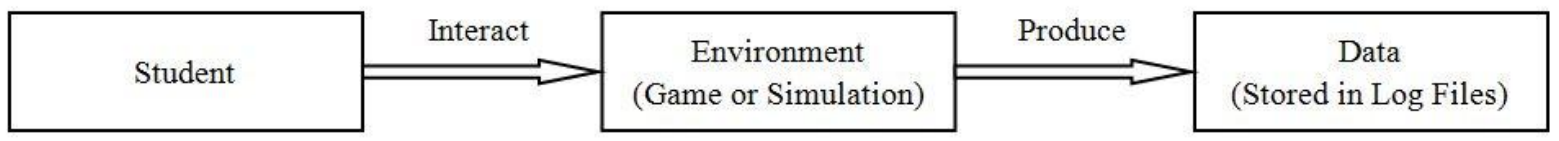

Figure 2: The Basic Process Framework

Students are the objects of assessment, bearing the content of the assessment. The assessment includes three parts: the skills improvement (learning outcomes), motivation and emotion, and metacognition. Assessment indicators of skills improvement include performance, skills score, competencies score, learning outcome, 


\section{Issues in Information Systems}

Volume 22, Issue 4, pp. 193-207, 2021

achievement, score, etc. Learning motivation and interest assessment indicators include learning attitudes, learning motivation, satisfaction or enjoyment, engagement, etc. Metacognitive assessment indicators include self-efficacy, perceived ability, perceived mastery of learning, and so on. Whether it be a game or simulation, the environment is the place where the interactions occur and the interactive environment $\log$ files store interactive data. The data in the log files mainly include the student behavioral data, decision data, and the characteristics of this data. Of course, the way of acquiring the interactive data can also be the comparison of the pre-test and post-test, questionnaires, surveys, and other means. Based on the PFMGBLAS, we incorporated the process framework into it and added the assessment method to get the Schematic FMGBLAS (Figure 3).

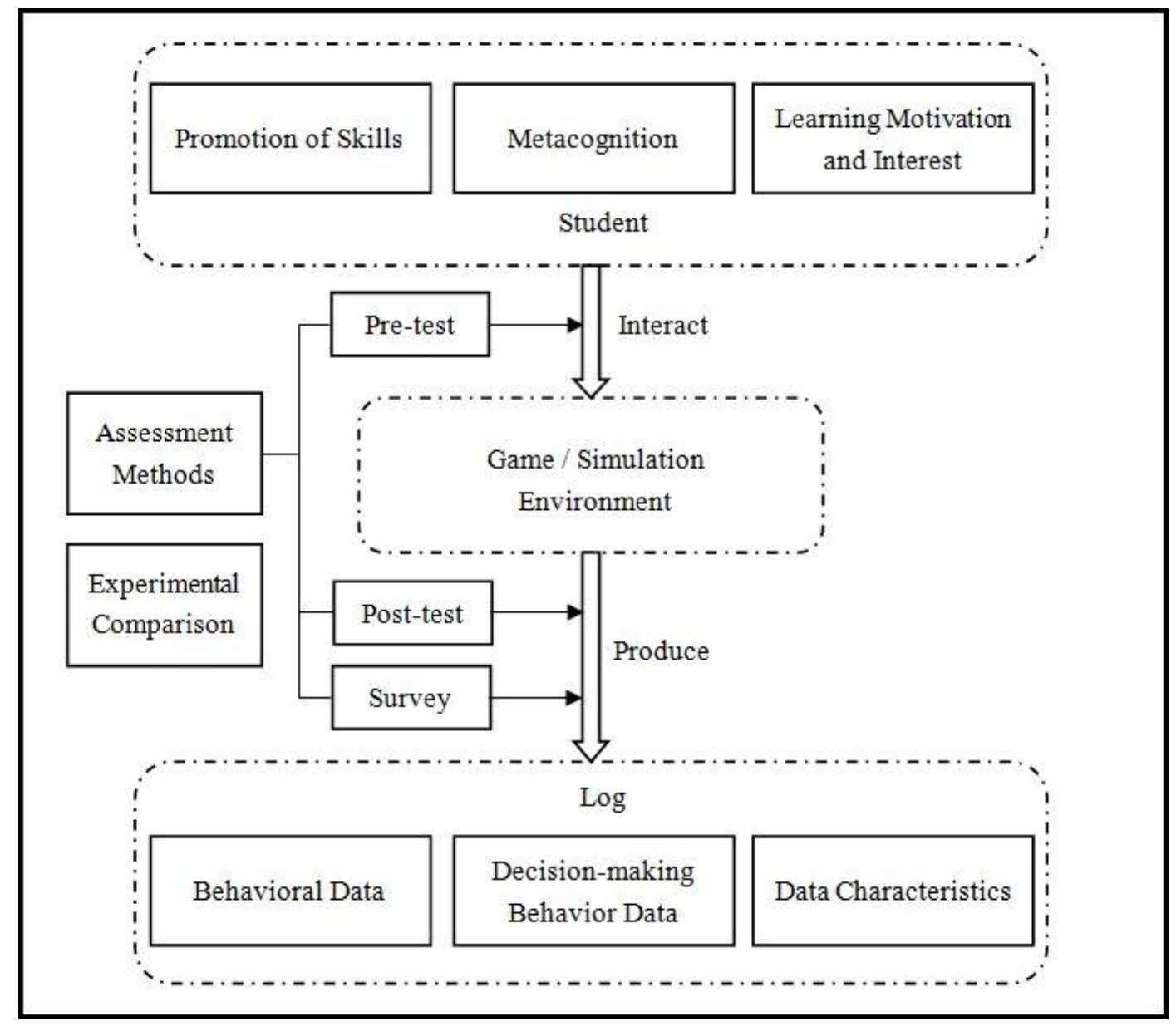

Figure 3: Schematic FMGBLAS

Assessment content is the core part of the assessment systems. In the process of game-based learning and assessment, students enter the process of solving problems in the game's simulation environment. Many studies have shown that skills improvement, including learning performance, academic performance, etc., is a specific manifestation of the students' cognitive level. Learning motivation and interest belong to the category of emotion. To make the assessment framework more inclusive and representative, we expand our assessment of students' skills improvement to cognitive assessment and expand the assessment of motivation and interest in learning into the emotional assessment. As a result, we frame the assessment of students into cognitive, metacognitive, and emotional aspects. We can evaluate the students' cognitive level by comparing the pre-test and post-test data. We can evaluate the emotion level and the metacognition level by the method of investigation. The results of the metacognitive assessment can be further reflected by the 


\section{Issues in Information Systems}

Volume 22, Issue 4, pp. 193-207, 2021

changes in the cognitive level. At the same time, all the assessments at these three levels rely heavily on the mining of $\log$ file interaction data as the focus of future research. Based on the above analysis, we can make the Schematic FGBLAS universal and clear, and form the FMGBLAS (Figure 4).

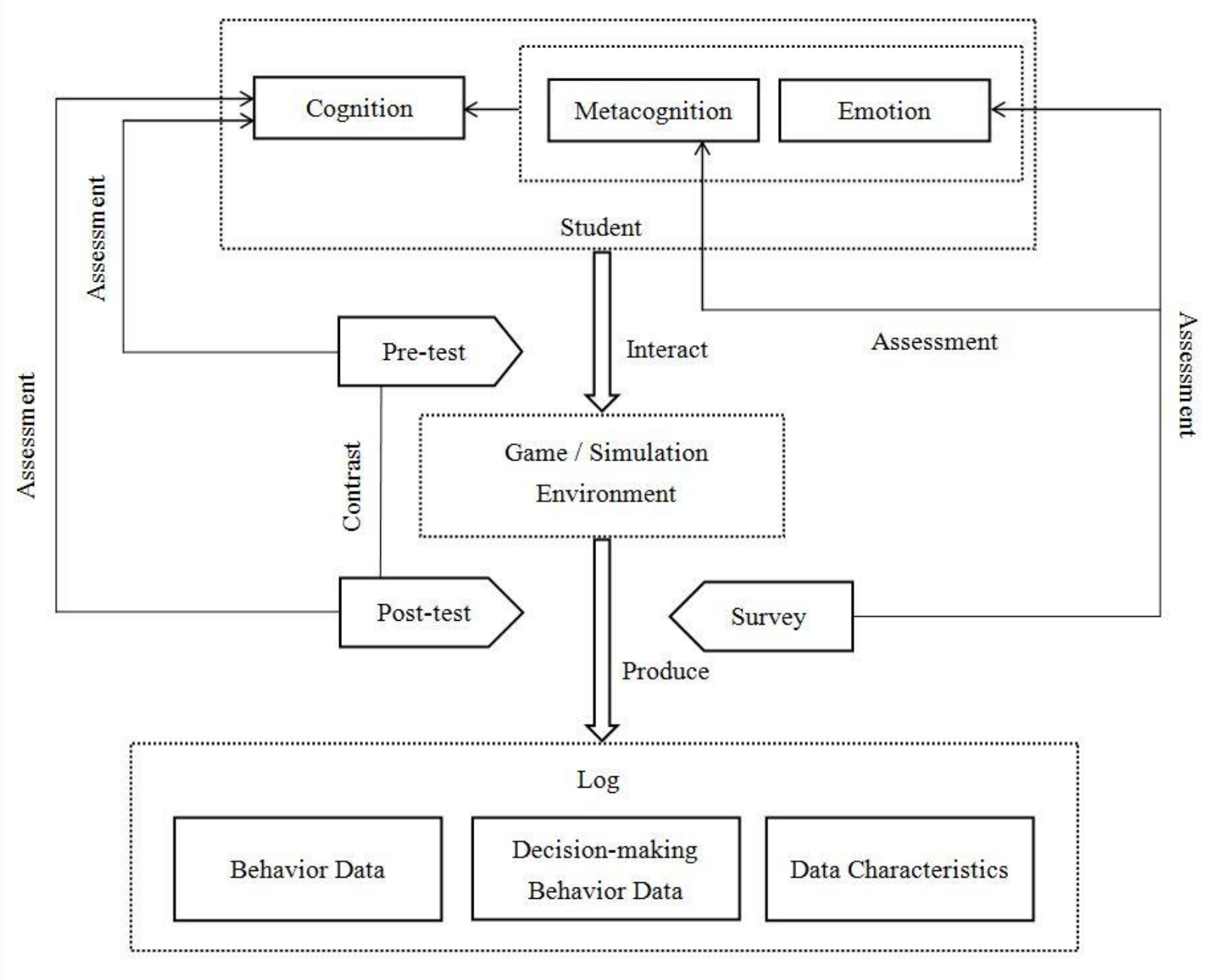

Figure 4: Framework Model of Game-Based Learning and Assessment Systems

Figure 4 illustrates the framework model of game-based learning and assessment systems. Students generate $\log$ files by interacting with games, which usually contain student behavior data, decision data, and data characteristics. The factors that affect the individual students mainly include cognition, metacognition, and emotion when the learning behavior occurs. Cognition is mainly reflected in the learners' previous knowledge framework and understanding of things. Metacognition is a deeper understanding of the student's cognitive processes. Emotion mainly refers to interest, hobbies, motivation, etc. How do we evaluate these aspects of the learners' cognition, metacognition, and emotion? The focus is on mining the log files for interactive behaviors. For the learners' cognition, we can test it through the $\log$ mining of pre-test and post-test data and compare it for the evaluation. For the assessment of the learners' emotion and metacognition, we can produce results through the form of the post-game investigation and the mining of the log files. The result of metacognition is also further reflected in the 


\section{Issues in Information Systems}

Volume 22, Issue 4, pp. 193-207, 2021

result of cognition. There are also models for the mining of log files, such as HMM (Hidden Markov Model), machine learning, and so on, that can be pursued.

\section{Conclusions}

In this paper, we collected and analyzed the relevant literature on educational game assessment. We looked at existing educational game assessment systems, contents, and methods, as well as the data mining process of game-based educational assessment. From our comparative analysis of related research, a basic framework model of game-based learning and assessment systems is proposed. The model focuses on the universality of game-based learning and assessment systems. It also highlights the important role of the interaction behavior log in the mining of learning data. In addition to this model being used for educational games, it could be extended to the learning and assessment systems based on a simulation environment. In the future, we plan to further explore the student data obtained from the simulation platform and make the appropriate corrections and amendments to our model.

\section{References}

Chang, C.-C., Liang, C., Chou, P.-N., \& Lin, G.-Y. (2017). Is game-based learning better in flow experience and various types of cognitive load than non-game-based learning? Perspective from multimedia and media richness. Computers in Human Behavior, 71, 218-227.

Chi, M. T. H. (1983). Problem solving abilities. http://www.dtic.mil/docs/citations/ADA134717

Csapó, B., \& Funke, J. (2017). The nature of problem solving: Using research to inspire 21 st century learning. Paris, France: OECD Publishing.

Dostál, J. (2015). Theory of problem solving. Procedia - Social and Behavioral Sciences, 174, 27982805.

Funke, J. (2010). Complex problem solving: A case for complex cognition? Cognitive Process, 11(2), 133-142.

Greiff, S., Wüstenberg, S., Csapó, B., Demetriou, A., Hautamäki, J., Graesser, A. C., \& Martin, R. (2014). Domain-general problem solving skills and education in the 21 st century. Educational Research Review, 13, 74-83.

Halverson, R., \& Owen, V. E. (2014). Game-based assessment: An integrated model for capturing evidence of learning in play. International Journal of Learning Technology, 9(2), 111-138.

Hummel, H. G. K., Brinke, D. J.-T., Nadolski, R. J., \& Baartman, L. J. (2017) Content validity of gamebased assessment: Case study of a serious game for ICT managers in training. Technology, Pedagogy and Education, 26(2), 225-240.

Kim, B., Park, H., \& Baek, Y. (2009). Not just fun, but serious strategies: Using meta-cognitive strategies in game-based learning. Computers \& Education, 52(4), 800-810.

Scherer, R., \& Tiemann, R. (2012). Factors of problem-solving competency in a virtual chemistry environment: The role of metacognitive knowledge about strategies. Computers \& Education, 59(4), 1199-1214. 


\section{Issues in Information Systems}

Volume 22, Issue 4, pp. 193-207, 2021

Shute, V. J. (2008). Focus on formative feedback. Review of Educational Research, 78(1), 153-189.

Shute, V. J. (2011). Stealth assessment in computer-based games to support learning. In J. D. Fletcher, \& S. Tobias (Eds.), Computer games and instruction (pp. 503-523). Charlotte, NC: Information Age Publishing.

Shute, V. J., Hansen, E. G., \& Almond, R. G. (2008). You can't fatten a hog by weighing it - Or can you? Evaluating an assessment for learning system called ACED. International Journal of Artificial Intelligence in Education, 18(4), 289-316.

Shute, V. J., \& Rahimi, S. (2017). Review of computer-based assessment for learning in elementary and secondary education. Journal of Computer Assisted Learning, 33(1), 1-19.

Squire, K. (2006). From content to context: Videogames as designed experience. Educational Researcher, $35(8), 19-29$.

Williamson, B. (2004). Book review: What video games have to teach us about learning and literacy. Technology, Pedagogy and Education, 13(1), 125-127.

Zheng, Q., Sun, H., Chen, Y., \& Liu, C. (2016). The construction and application of an online learning evaluation system based on learning analytics technology: A study of comprehensive modeling method. e-Education Research, 12(5), 40-45.

Zuo, H. (2016). The international trend of curriculum reform of basic education: Go toward core literacy. Curriculum, Teaching Material and Method, 36(2), 39-46.

\section{Appendix A: Relevant Literature from Computers \& Education}

$\begin{array}{ll}\begin{array}{l}\text { Numbe } \\ \mathrm{r}\end{array} & \text { Article } \\ 1 & \text { Adams, D. M., \& Clark, D. B. (2014). Integrating self-explanation functionality into a } \\ & \text { complex game environment: Keeping gaming in motion. Computers \& Education, 73, 149- } \\ & 159 .\end{array}$




\section{Issues in Information Systems}

Volume 22, Issue 4, pp. 193-207, 2021

8

9

10

11

12

13

Castellar, E. N., All, A., de Marez, L., \& Van Looy, J. (2015). Cognitive abilities, digital games and arithmetic performance enhancement: A study comparing the effects of a math game and paper exercises. Computers \& Education, 85, 123-133.

Chen, C.-H., \& Chiu, C.-H. (2016). Employing intergroup competition in multitouch designbased learning to foster student engagement, learning achievement, and creativity. Computers \& Education, 103, 99-113.

Cheng, M.-T., Lin, Y.-W., \& She, H.-C. (2015). Learning through playing Virtual Age: Exploring the interactions among student concept learning, gaming performance, in-game behaviors, and the use of in-game characters. Computers \& Education, 86, 18-29.

Clark, D. B., Virk, S. S., Barnes, J., \& Adams, D. M. (2016). Self-explanation and digital games: Adaptively increasing abstraction. Computers \& Education, 103, 28-43.

Corral, J. M. R., Balcells, A. C., Estévez, A. M., Moreno, G. J., \& Ramos, M. J. F. (2014). A game-based approach to the teaching of object-oriented programming languages. Computers \& Education, 73, 83-92.

3 Denner, J., Werner, L., \& Ortiz, E. (2012). Computer games created by middle school girls: Can they be used to measure understanding of computer science concepts? Computers \& Education, 58(1), 240-249.

Erhel, S., \& Jamet, E. (2013). Digital game-based learning: Impact of instructions and feedback on motivation and learning effectiveness. Computers \& Education, 67, 156-167. Feldman, J., Monteserin, A., \& Amandi, A. (2014). Detecting students' perception style by using games. Computers \& Education, 71, 14-22.

Filsecker, M., \& Hickey, D. T. (2014). A multilevel analysis of the effects of external rewards on elementary students' motivation, engagement and learning in an educational game. Computers \& Education, 75, 136-148.

Furió, D., González-Gancedo, S., Juan, M.-C., Seguí, I., \& Rando, N. (2013). Evaluation of learning outcomes using an educational iPhone game vs. traditional game. Computers \& Education, 64, 1-23.

Guo, Y. R., \& Goh, D. H.-L. (2016). Evaluation of affective embodied agents in an information literacy game. Computers \& Education, 103, 59-75.

Hainey, T., Westera, W., Connolly, T. M., Boyle, L., Baxter, G., Beeby, R. B., \& Soflano, M. (2013). Students' attitudes toward playing games and using games in education: Comparing Scotland and the Netherlands. Computers \& Education, 69, 474-484. Hooshyar, D., Ahmad, R. B., Yousefi, M., Fathi, M., Horng, S.-J., \& Lim, H. (2016). Applying an online game-based formative assessment in a flowchart-based intelligent tutoring system for improving problem-solving skills. Computers \& Education, 94, 18-36. Hwang, G.-J., Chiu, L.-Y., \& Chen, C.-H. (2015). A contextual game-based learning approach to improving students' inquiry-based learning performance in social studies courses. Computers \& Education, 81, 13-25. Hwang, G.-J., Hsu, T.-C., Lai, C.-L., \& Hsueh, C.-J. (2016). Interaction of problem-based gaming and learning anxiety in language students' English listening performance and progressive behavioral patterns. Computers \& Education, 106, 26-42.

Hwang, G.-J., \& Wang, S.-Y. (2016). Single loop or double loop learning: English vocabulary learning performance and behavior of students in situated computer games with different guiding strategies. Computers \& Education, 102, 188-201.

Hwang, G.-J., Wu, P.-H., \& Chen, C.-C. (2012). An online game approach for improving students' learning performance in web-based problem-solving activities. Computers \& Education, 59(4), 1246-1256. 


\section{Issues in Information Systems}

Volume 22, Issue 4, pp. 193-207, 2021

Hwang, G.-J., Yang, L.-H., \& Wang, S.-Y. (2013). A concept map-embedded educational computer game for improving students' learning performance in natural science courses. Computers \& Education, 69, 121-130.

26 Hwang, M.-Y., Hong, J.-C., Cheng, H.-Y., Peng, Y.-C., \& Wu, N.-C. (2013). Gender differences in cognitive load and competition anxiety affect 6th grade students' attitude toward playing and intention to play at a sequential or synchronous game. Computers \& Education, 60(1), 254-263.

Kim, H. J., \& Jang, H. Y. (2015). Factors influencing students' beliefs about the future in the context of tablet-based interactive classrooms. Computers \& Education, 89, 1-15.

Kim, Y. J., \& Shute, V. J. (2015). The interplay of game elements with psychometric qualities, learning, and enjoyment in game-based assessment. Computers \& Education, 87, 340-356.

Law, V., \& Chen, C.-H. (2016). Promoting science learning in game-based learning with question prompts and feedback. Computers \& Education, 103, 134-143.

Le Hénaff, B., Michinov, N., Le Bohec, O., \& Delaval, M. (2015). Social gaming is inSIDE: Impact of anonymity and group identity on performance in a team game-based learning environment. Computers \& Education, 82, 84-95.

Meluso, A., Zheng, M., Spires, H. A., \& Lester, J. (2012). Enhancing 5th graders' science content knowledge and self-efficacy through game-based learning. Computers \& Education, 59(2), 497-504.

Ozcelik, E., Cagiltay, N. E., \& Ozcelik, N. S. (2013). The effect of uncertainty on learning in game-like environments. Computers \& Education, 67, 12-20.

Peng, W., Song, H., Kim, J., \& Day, T. (2016). The influence of task demand and social categorization diversity on performance and enjoyment in a language learning game. Computers \& Education, 95, 285-295.

4 Robertson, J. (2012). Making games in the classroom: Benefits and gender concerns. Computers \& Education, 59(2), 385-398.

5 Ronimus, M., Kujala, J., Tolvanen, A., \& Lyytinen, H. (2014). Children's engagement during digital game-based learning of reading: The effects of time, rewards, and challenge. Computers \& Education, 71, 237-246.

6 Sampayo-Vargas, S., Cope, C. J., He, Z., \& Byrne, G. J. (2013). The effectiveness of adaptive difficulty adjustments on students' motivation and learning in an educational computer game. Computers \& Education, 69, 452-462. Schmitz, B., Schuffelen, P., Kreijns, K., Klemke, R., \& Specht, M. (2015). Putting yourself in someone else's shoes: The impact of a location-based, collaborative role-playing game on behaviour. Computers \& Education, 85, 160-169.

Smith, G. G., Li, M., Drobisz, J., Park, H.-R., Kim, D., \& Smith, S. D. (2013). Play games or study? Computer games in eBooks to learn English vocabulary. Computers \& Education, 69, 274-286.

9 Snow, E. L., Allen, L. K., Jacovina, M. E., \& McNamara, D. S. (2015). Does agency matter?: Exploring the impact of controlled behaviors within a game-based environment. Computers \& Education, 82, 378-392.

Soflano, M., Connolly, T. M., \& Hainey, T. (2015a). An application of adaptive gamesbased learning based on learning style to teach SQL. Computers \& Education, 86, 192-211. Soflano, M., Connolly, T. M., \& Hainey, T. (2015b). Learning style analysis in adaptive GBL application to teach SQL. Computers \& Education, 86, 105-119.

Sung, H.-Y., \& Hwang, G.-J. (2013). A collaborative game-based learning approach to improving students' learning performance in science courses. Computers \& Education, 63, 43-51. 


\section{Issues in Information Systems}

Volume 22, Issue 4, pp. 193-207, 2021

43 Ventura, M., Shute, V., \& Zhao, W. (2013). The relationship between video game use and a performance-based measure of persistence. Computers \& Education, 60(1), 52-58.

44 Wang, A. I. (2015). The wear out effect of a game-based student response system. Computers \& Education, 82, 217-227.

45 Warren, S. J., Dondlinger, M. J., McLeod, J., \& Bigenho, C. (2012). Opening The Door: An evaluation of the efficacy of a problem-based learning game. Computers \& Education, $58(1), 397-412$.

46 Wouters, P., \& Van Oostendorp, H. (2013). A meta-analytic review of the role of instructional support in game-based learning. Computers \& Education, 60(1), 412-425.

47 Yang, Y.-T. C. (2015). Virtual CEOs: A blended approach to digital gaming for enhancing higher order thinking and academic achievement among vocational high school students. Computers \& Education, 81, 281-295.

48 Yang, Y.-T. C., \& Chang, C.-H. (2013). Empowering students through digital game authorship: Enhancing concentration, critical thinking, and academic achievement. Computers \& Education, 68, 334-344. 